\title{
REVIEW OF MACHINING METAL MATRIX COMPOSITES
}

\author{
C.J. Nicholls, B. Boswell, I. Davies, M.N. Islam \\ Department of Mechanical Engineering, Curtin University, \\ GPO Box U1987, Perth, WA 6845, Australia
}

\begin{abstract}
Metal Matrix Composites (MMC) is a material which has been widely used in the aerospace and automobile industries since the 1980s, and has been classified as a hard to machine material. During the intervening years only a limited amount of research has been conducted into the cutting action of MMCs. As with traditional materials it is important to understand the wear mechanisms that contribute to tool wear reducing tool life. This review has been carried out to establish the optimum machining parameters vital to maximizing tool life whilst producing parts at the desired quantity and quality. The objective of this research is to evaluate the effectiveness of the machining parameters for these hard to machine material MMC.
\end{abstract}

Keywords: Metal Matrix Composites, machining parameters, wear mechanisms, hard to machine material, tool life. 


\subsection{Introduction}

Metal Matrix Composites (MMCs) are a relatively new category of composite material that consists of a ductile metal matrix reinforced by strong particles, fibers or whiskers [1, $2 \& 3]$. Common matrix metals include aluminum, titanium, magnesium, cobalt, copper and various alloys of these materials. The reinforcement material is generally a brittle ceramic material, typical examples include Silicone Carbide $(\mathrm{SiC})$ and Boron Carbide $\left(\mathrm{B}_{4} \mathrm{C}\right)$ and more recently, TiC $[4,5]$. MMCs are increasingly desired for their improved specific properties that combine the toughness and ductility of the metal matrix phase with the hardness and strength of the reinforcement phase $[6,7]$. Increasing the demand for MMCs materials to be used for aerospace machined products. However, as yet to full explanation of several unique machining properties of MMCs remain unsolved. Giving rise to conflicting reports on certain characteristics of MMCs [8] during cutting, it is generally agreed that they are very difficult to machine [9]. Research into improving or quantifying the machinability characteristics of MMCs have been performed since the early 1970s, with Figure 1a showing the steady increase of studies completed based on available papers.

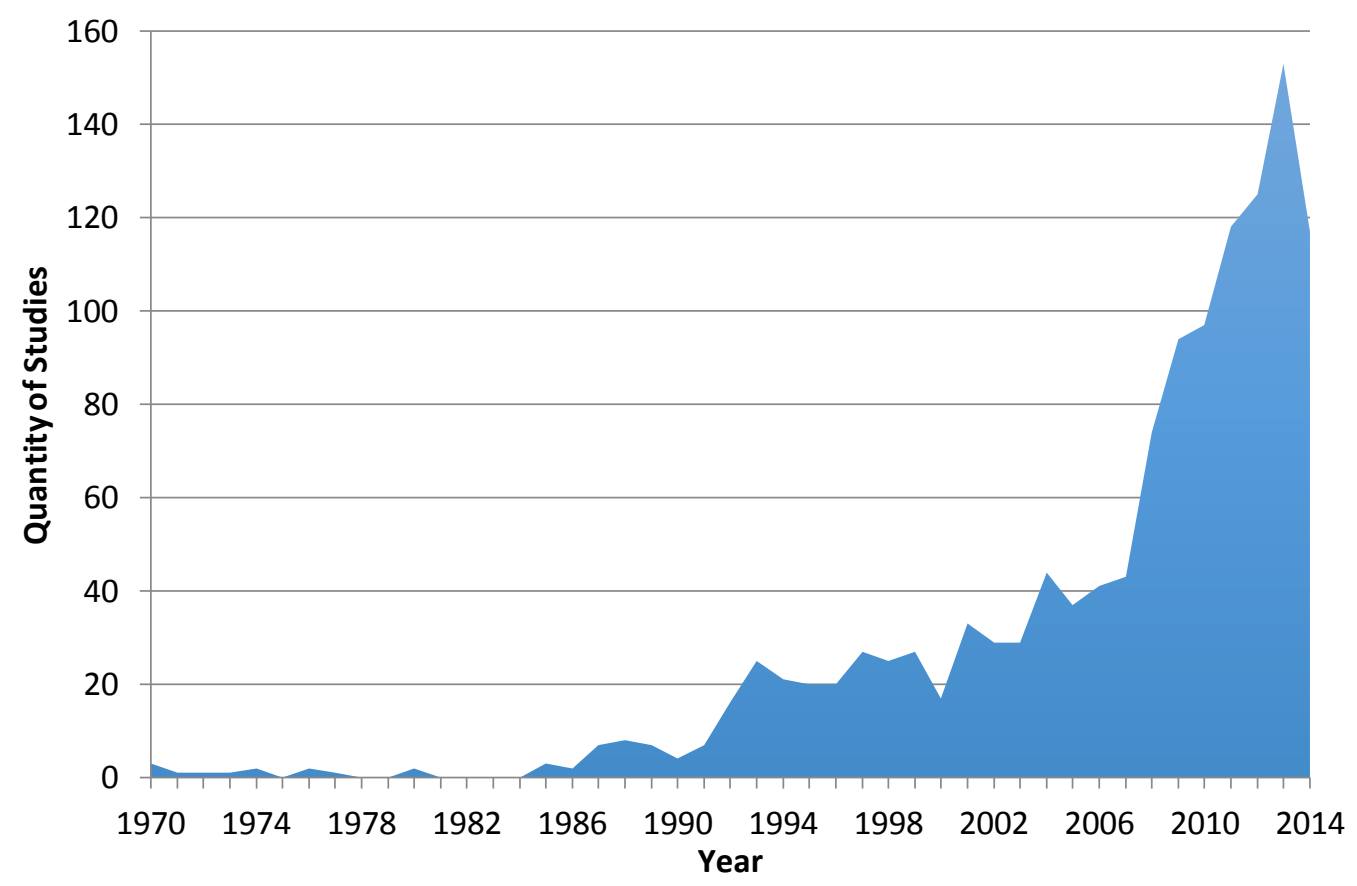

Figure 1a: Volume of MMC machinability studies by year sourced from a variety of journals database and web sites

MMCs have in recent times become commonplace in the aerospace, and performance automobile industries [10], where the high cost of machining the material can be afforded. 
However, a wider product base of using MMCs has been extensively disrupted by the difficulties associated with the material's machinability [4]. The conventional single-shear plane cutting models are unsuitable for modeling the cutting process of MMCs during machining [11]. Very few attempts have been made into generating predictive models for the behavior of MMCs during the machining process [12-15]. Further study into the prediction of the machining forces, and machining parameters are required to fully understand the behaviour of the material [16]. This review considers numerous research investigations which have been conducted throughout many industrial countries as shown in Figure $1 \mathrm{~b}$ in determining the effects of the machining parameters, and machinability of MMC material.

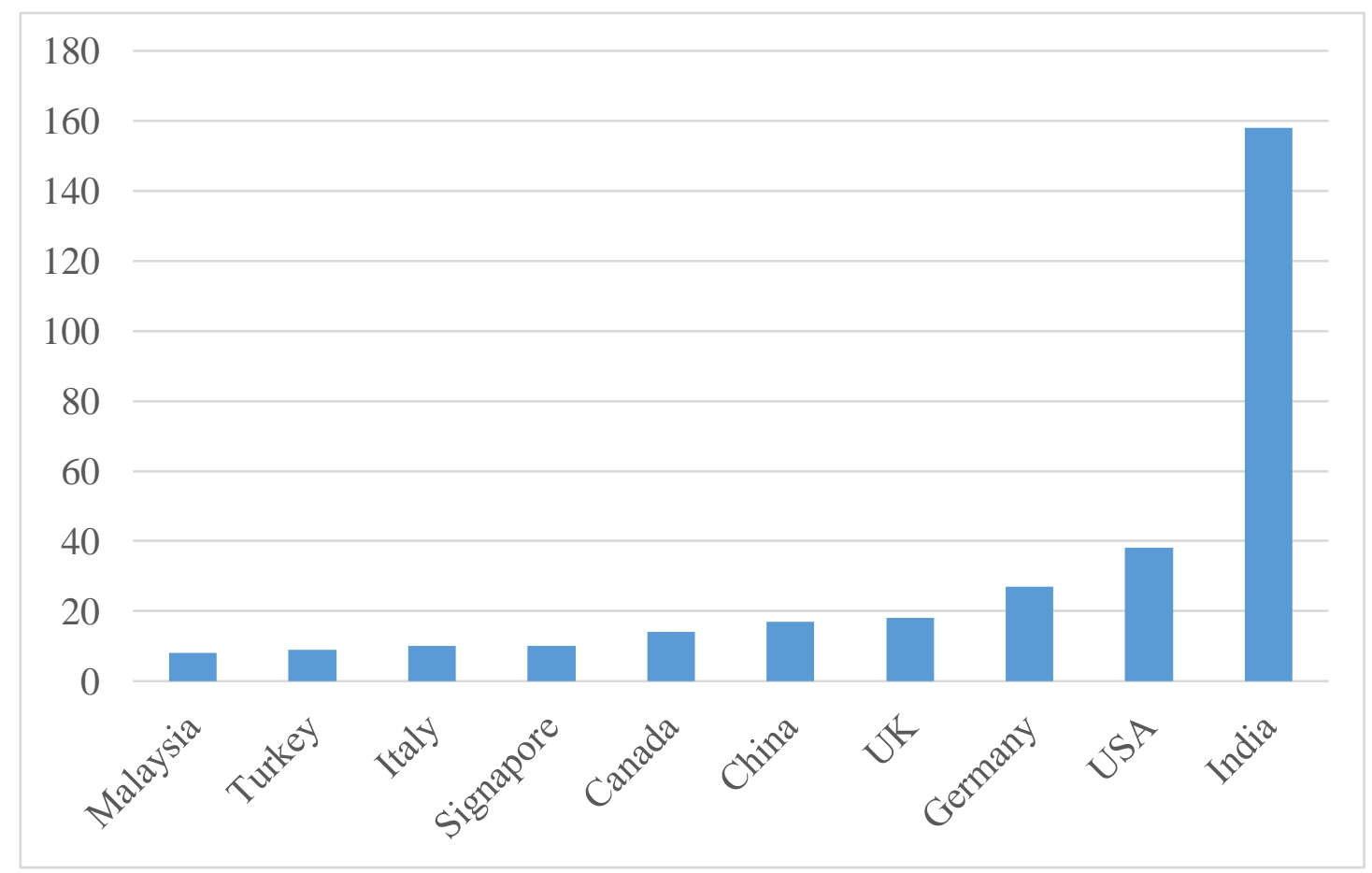

Figure 1b: Distribution of research performed over the previous 20 years thought the world, data retrieved from Scopus database search with the phrase [MMC machining parameters]

\subsection{Effects of Tool Selection}

The majority of investigations into MMC machinability have been performed using cemented carbide or polycrystalline diamond (PCD) as the cutting tool material. Figure 2 shows the distribution of the tool types used during cutting process for the experimental machining tests surveyed in this review. 


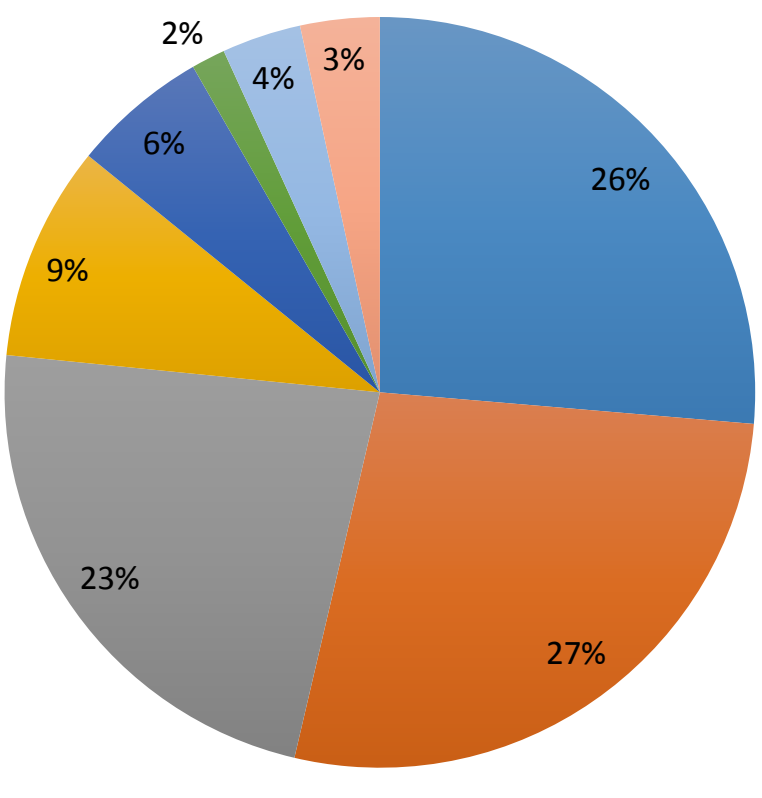

Uncoated Tungsten Carbide

Coated Tungsten Carbide

Polycrystalline Diamond

Crystal Vapour Deposition

Cubic Boron Nitride

Mono-Crystalline Diamond

- Ceramic

High Speed Steel

Figure 2: Tool type used in the machining of MMCs from journals

The majority of studies were conducted on lathes, with the next favored machine tool being the vertical mill in addition to milling there were some drilling operations being examined. The recommend twist drill used was normally PCD diamond coated. However, many studies contend that carbide tools are a suitable alternative under certain conditions [17]. This is especially useful since carbide tip are cheaper, and tool wear starts relatively quickly allowing different parameters to be examined to determine their suitability. Which is obviously ideal for examining cooling methods in determining if the onset of the wear mechanisms have been slowed down or not. The studies revealed that carbide tools were used 53\% over other materials, and from the papers surveyed coated or uncoated carbide tips where evenly used. Studies into the feasibility of high speed steel (HSS) and ceramic tools have found them both to be unsuitable for MMC applications [17-19], as ceramic tips are brital and HSS wear too quickly. However, TiN coated HSS tools can be economic for short run production [20] and twist drills. Cubic Boron Nitride (CBN) has also been investigated as a potentially viable tool material however testing indicates that PCD tools are more appropriate [21-23] and is the most suitable tip material for production purposes.

\subsection{Cemented Carbide Tools}

The feasibility of using cemented carbide tools to machine MMCs is a point of contention among the scientific community. It has been suggested that cemented carbide tools are not 
suited to the machining of MMCs by many researchers [24-26]. A number of conflicting studies have concluded that carbide tools are useful for machining MMCs under certain conditions [27-29]. Carbide tools have been found to be effective in short run machining operations [30, 31] or for roughing operations [32]. It has also been proposed that they perform with industrially acceptable tool life at low cutting speeds $(20-30 \mathrm{~m} / \mathrm{min})$ and high feed rates when machined using a lathe [19]. Certain carbide tools at cutting speeds of $250 \mathrm{~m} / \mathrm{min}$ have been observed with a tool life of 40 min when lathe machining Al-SiC based composites [33]. Hung et al. performed investigations into various tooling types and concluded carbide type tools to be the most economical method for machining MMCs [34]. Figure 3 displays the results attained for tool life from these experiments.

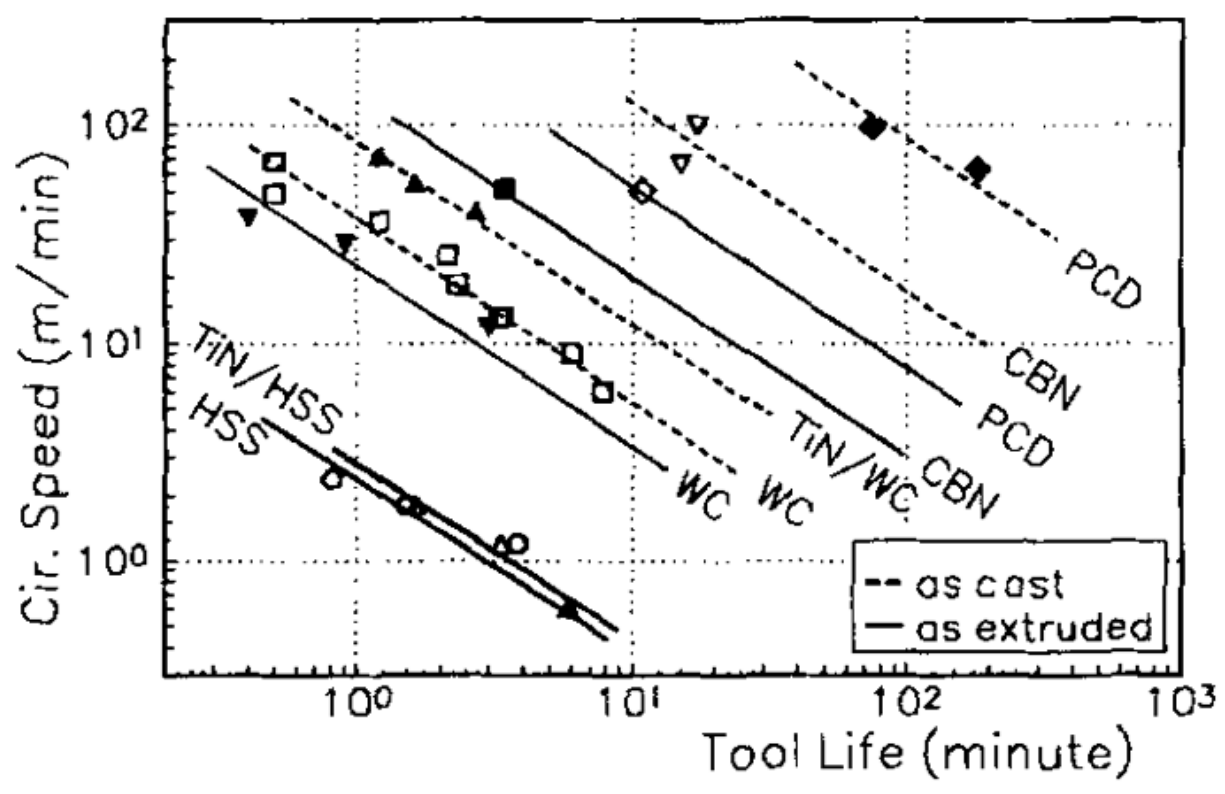

Figure 3: Tool life vs. cutting speed for selected tool material types [34]

An investigation conducted by Chambers [35] using K10 carbide tools at cutting speeds between 20 and $1000 \mathrm{~m} / \mathrm{min}$ upon $\mathrm{Al} \mathrm{5 \%} \mathrm{Mg/Saffil} \mathrm{supported} \mathrm{the} \mathrm{use} \mathrm{of} \mathrm{cemented} \mathrm{carbide}$ tools. The study also noted subsurface damage extending to a depth of $20 \mu \mathrm{m}$ which was not related to the particle reinforcement fraction or the cutting speed. Limited investigations have been performed into the use of carbide drills [36-39]. A study by McGinty and Preuss [36] found that carbide drills were capable of producing 120 holes through a material $12.7 \mathrm{~mm}$ thick at cutting speeds between 8 and $30 \mathrm{~m} / \mathrm{min}$ using feed rates between 0.15 to $0.3 \mathrm{~mm} / \mathrm{rev}$ with acceptable levels of wear. 
Carbide tools with ceramic coatings have been successfully applied to the machining of steels for decades, yielding significant improvements over the use of uncoated carbide tools. In conventional machining scenarios, they have been known to have a tool life upwards of $200-$ $300 \%$ that of an uncoated tool [40]. Investigations into the use of coated carbide tool tips while machining MMCs have concluded that the coating has little effect upon the tool life due to the rapidity of the removal of the coating through wear [41,42]. Sun et al. reported acceptable tool lives with respect to wear using coated carbide tools [43]. This conclusion is contradicted by a study performed by certain research, which identified coated carbide tools as yielding improved tool life $[44,45]$. It has been suggested that the use of carbide coated tools yields improvements in the surface finish of the machined MMC material over the use of uncoated carbide tooling [46]. Several studies have identified the primary mechanism of wear on tools while machining MMCs as being abrasion [33, 47, 48]. As such, any improvements in the lifespan of a tool will be exhibited as a function of an increase in the hardness of the tool tip or the coating applied to it [17].

\subsection{Polycrystalline Diamond Tooling}

Polycrystalline Diamond (PCD) tools have been used for the machining of MMCs for many years with much success [49-54]. This success is has been attributed to the fact that the hardness of PCD tool tips is greater than the majority of reinforcing particles and fibers that make up the reinforcement phase $[55,56]$. There is a general consensus among researchers that the use of PCD tooling offers a significant increase in tool life over carbide tools, making it the ideal tool material for machining MMCs [51, 57-59]. The tool life of various tool materials as shown in Figure 3 clearly showed that PCD tools provided the longest tool life.

A study by Chambers and Stephens [60] found that PCD tools were far superior to other tool types when machining an aluminum-based, $5 \%$ Saffil, $12 \% \mathrm{SiC}$ material on a lathe. While most studies have found that PCD tooling yielded an improvement in tool life, Chen and Miyake [61] noted that the improvement in tool life was far less than expected while testing an Al-Mg5 alloy reinforced with $20 \%$ Saffil on a lathe. The life of the tool was only doubled, in contrast to significant gains in tool life when machining conventional materials.

Chambers and Stephens [60] observed the primary wear mechanism while machining MMCs with PCD tools to be abrasion. Many other studies suggested that the wear observed was primarily abrasive $[33,35,62,63]$. One study identified microchipping in a PCD tool and 
therefore concluded that increasing feed rate and depth of cut to maximize material removal rate (MRR) would be unsuccessful. This conclusion contrasts the findings from studies into carbide tool tips, which suggest maximizing these quantities to improve MRR over the lifespan of the tool. Increases in cutting speed have been shown to yield an increase in the rate of tool wear similar to that of carbide tools [64].

\subsection{Chemical Vapour Deposition Tooling}

Diamond coated tools created using the Chemical Vapour Deposition (CVD) method have also been investigated as a suitable tool tip for machining MMCs. Andrews et al. [65] compared CVD tools to PCD and noted significant lack of performance from CVD tooling. A comparison of PCD and CVD tools using carbide tool performance as a reference point found that CVD tools performed unsatisfactorily [18]. The study concluded that while the CVD tools showed improved tool life, PCD tools had twice the useful lifespan due to the tendency of the diamond coating on CVD tools to detach during machining. Investigations by Kremer \& El Mansori determined that the use of rough or multi-layered CVD coatings yielded lower machining forces than using smooth coatings while machining SiC reinforced aluminium [66].

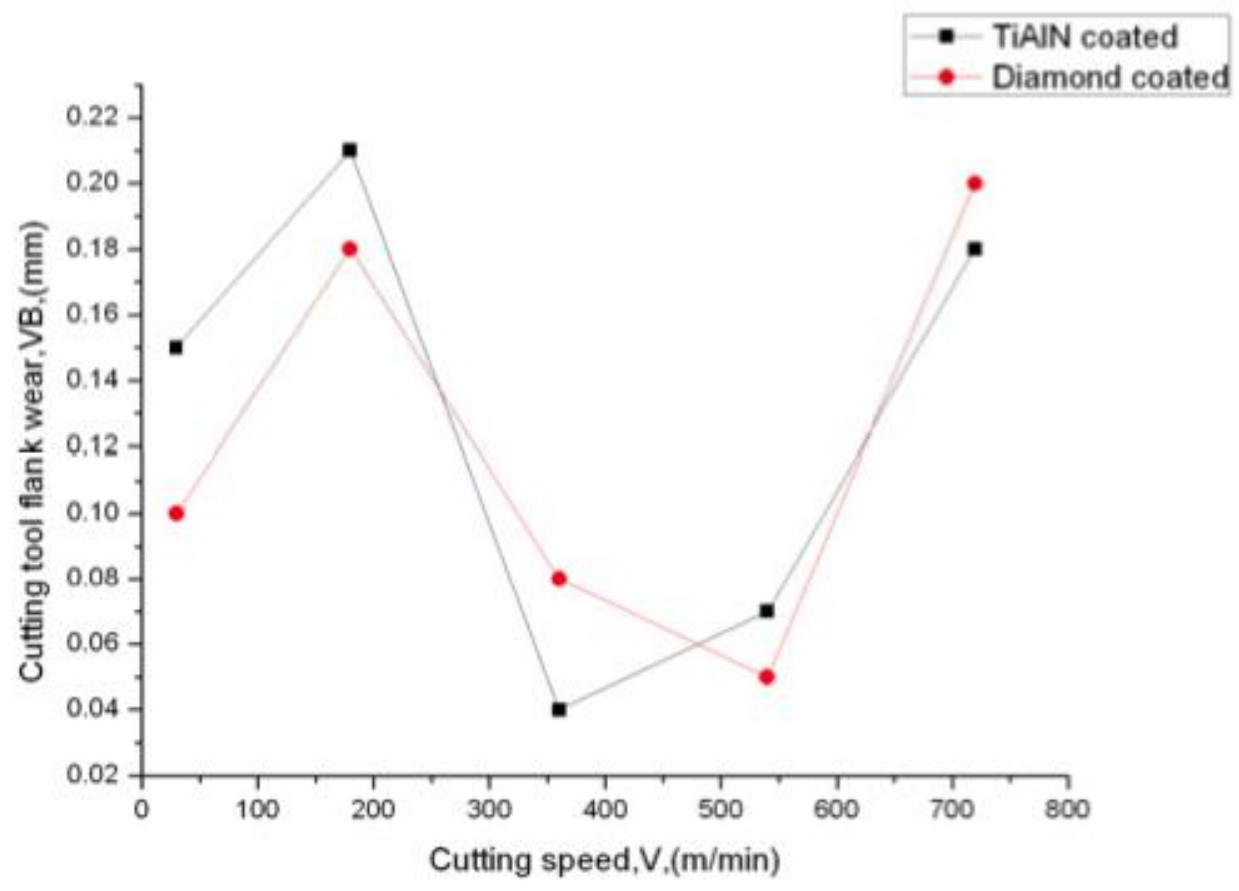

Figure 4: Tool flank wear of coated carbide and CVD tools for the same material removal 
Figure 4 shows a comparison between flank tool wear on a coated carbide tools and CVD tool tip. A study into the behavior of CVD tools while machining MMCs suggested that the primary failure mode at low cutting speeds is coating failure, while at high speeds the primary failure mode is edge chipping [67]. The same study also observed that at milling speeds above 720 $\mathrm{m} / \mathrm{min}$, CVD tools are highly prone to rapid and catastrophic edge chipping, resulting in tool failure. Coating failure was identified as a major issue for wear while machining MMCs with CVD tooling during additional studies [68]. Another study by Chou \& Liu also identifies coating failure as a major issue in the use of CVD tools [69]. Research performed by J. Paulo Davim suggest that CVD tooling developed catastrophic levels of flank wear 10 times faster than PCD tooling, making CVD a far less desirable option for the machining of MMCs [3].

\subsection{Cubic Boron Nitride Tooling}

Cubic Boron Nitride $(\mathrm{CBN})$ tools have a much greater hardness than conventional carbide tools, but are not as hard as PCD tools [70]. CBN tools have been compared against carbide and PCD tooling, and were found to perform similarly to uncoated carbide tools in certain work $[21,15]$. In a study comparing CBN tools to PCD on a lathe at 50 and $400 \mathrm{~m} / \mathrm{min}$ with a depth of cut of $0.3 \mathrm{~mm}$ and $0.1 \mathrm{~mm} / \mathrm{rev}$ feed rate, PCBN tools suffered from significantly larger built up edge and suffered from a shorter tool life [22]. These findings are in conflict with more recent work by Hung et al. and Looney [27, 71]. Hung tested multiple tool materials on a lathe and found the use of CBN tools improved useful tool life by a factor of almost 5. The same study showed that PCD tools yielded a lifespan improvement at a factor close to 5 over CBN tools. Chipping of the tool tip was identified as an issue while machining with CBN tools [27]. This observation was supported by Ciftci et al. [21] who identified tool fracture as being the primary wear mode in a CBN tool while machining an aluminum, 16\% SiC MMC with reinforcement particle sizes of $110 \mu \mathrm{m}$. During the same study, abrasive flankwear was identified as the primary wear mode while machining material with $30 \mu \mathrm{m}$ and $45 \mu \mathrm{m}$ sized reinforcement particles. Research performed with CBN tool material has been found to be very limited with data retrieved from Scopus database only finding two studies each in India and Turkey and one from China, using the search phrase (tool life when machining MMC material).

\subsection{Effects of Machining Parameters}

One key step towards maximising the efficiency and sustainability of the process of machining MMCs is to optimise the machining parameters [72]. Matching the machining parameters to the tool material and the desired surface finish is vital to establishing an economically 
machining process. The optimisation of the machining parameters also improves the sustainability of the cutting operation, a factor which is becoming increasingly critical in the machining and fabrication industry [29]. Research reports generally good surface finish from machined MMCs [73, 74] however work by Cheung et al. have shown that in circumstances where the reinforcing fibers or particles are pulled from the workpiece during machining, the surface finish may deteriorate [75].

\subsection{Cutting Speed}

Investigations into the effects of cutting speed on abrasive flank wear have shown that minimum wear is achieved by optimising cutting speed, rather than by simply minimising or maximising it [76]. Ciftci, Turker and Seker trialled multiple cutting speeds on a lathe with a constant feed rate and depth of cut of $0.12 \mathrm{~mm} / \mathrm{rev}$ and $1 \mathrm{~mm}$, respectively. They found that machining at cutting speeds of $150 \mathrm{~m} / \mathrm{min}$ produced less flank wear than cutting at speeds of $100 \mathrm{~m} / \mathrm{min}$ or $200 \mathrm{~m} / \mathrm{min}$ [21]. A study by Pandi \& Muthusami suggests that surface roughness is also improved at medium cutting speeds [77]. Other studies suggest that increases in cutting speed will improve surface finish [78-82]. Figure 5 shows the surface roughness at various feed rates and cutting speeds was observed by Kaarmuhilan et al. to support the use of medium cutting speeds [50].

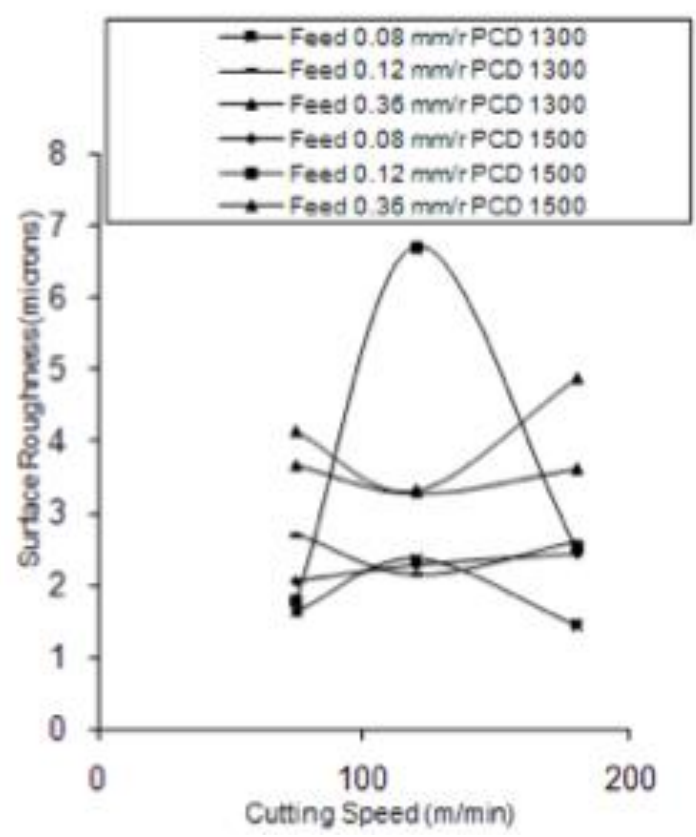

Figure 5: Cutting Speed versus Surface Roughness [50] 
Many studies have suggested that lowing cutting speeds will produce less tool wear $[80,83$, 84] by diffusion, during the machining of metal matrix composites. Diffusion wear becomes an issue as the tool material softens during high temperature machining [85]. It has been shown that high cutting speeds are primarily responsible for softening of the tool tip due to the temperatures generated at high speeds [86]. Research has shown cutting speed to be the primary parameter to influence the required machining power $[29,87,88]$. The same work identified $100 \mathrm{~m} / \mathrm{min}$ as the preferred cutting speed on a lathe for good surface finish. However, it was recommended to use higher cutting speeds to improve sustainability of the cutting process. The cutting speed is also the major contributor to cutting force according to an analysis performed by machining $\mathrm{Al} / \mathrm{SiC} / \mathrm{B} 4 \mathrm{C}$ material on a lathe [89]. The aforementioned cutting test recommended the cutting speed to be $100 \mathrm{~m} / \mathrm{min}$ ideally when using PCD tool tips.

The cutting speed has been identified as the primary influence upon the wear mechanisims of the cutting process [90]. The size of a built-up edge has been found to be highly dependent upon cutting speed. It has been observed that the size of the built-up edge formation is inversely proportional to the cutting speed of the machining operation [91, 92]. The results of the same research also supported the conclusion that built-up edge was detrimental to the surface finish of the workpiece and therefore cutting speed should be kept high to avoid poor surface finish. It appears that the selection of cutting speed must therefore take into account three primary factors; the desirability of a built-up edge, the importance of surface finish and the importance of tool life. Lower cutting speeds seem to improve tool life and develop built-up edge, however higher cutting speeds improve the surface finish of the machined product.

\subsection{Effect of Feed Rate}

Studies have shown that at higher feed rates, the rate of abrasive wear on the cutting tool decreases [93-96]. One of these studies attributes the decrease in wear to the thermal softening of the workpiece material as interface temperature rises [19]. Lin, Bhattacharyya and Lane suggest that the feed rate will also make a significant contribution to the thermal softening of the tool material [97]. Another study suggests that the decrease in wear at high feed rate is caused by the reduction of contact between the tool tip and the abrasive particles of the dispersed phase of the material [98]. Studies have also shown that the effect of feed rate is not as significant as cutting speed upon the usable tool life [63, 99]. A study performed using a lathe by Pendse \& Joshi found feed rate to be the primary influence upon surface finish [100]. Figure 6 shows the effect of feed rate upon specific cutting force as observed by Gaitonde $e t$ 
$a l .$. The trends in this figure show that an increase in feed rate had an overall reduction in the specific cutting force [101].
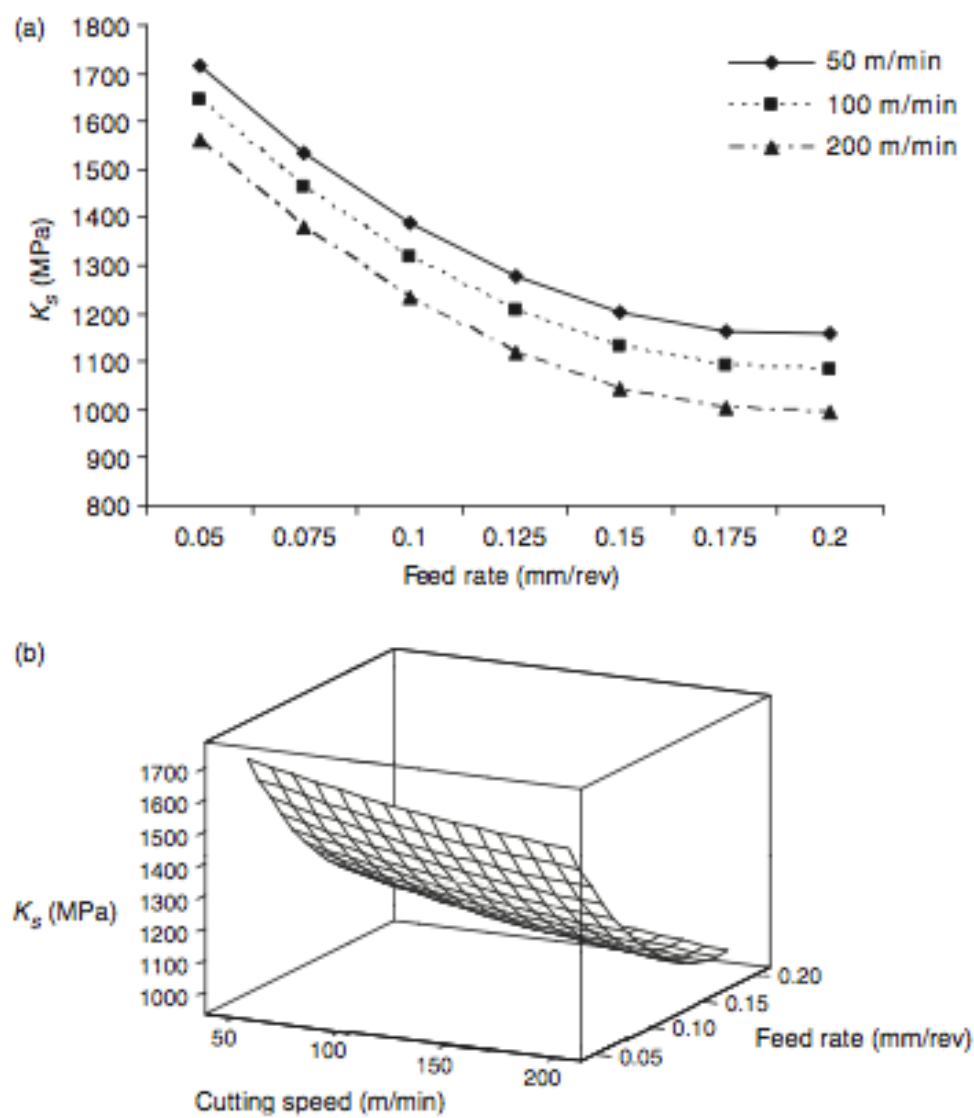

Figure 6: Effect of cutting speed and feed rate on specific cutting force [101]

Feed rate has been identified as a major contributor to the machining power [101]. Many studies into optimising the parameters of MMC machining have identified the feed rate as the parameter that contributes the most to the cutting force [29, 37, 38, 102]. Radhika et al. used ANOVA to conclude that feed rate had the highest influence upon the surface roughness when machining MMCs [103]. Chandrasekaran and Devarasiddappa performed mill tests and used fuzzy logic in their analysis. They identified feed rate as the main contributor to surface finish and recommended minimizing it to improve the quality of the finish [104]. This suggestion is supported by Kilickap et al. and Srinivasan et al. [80, 105]. Multiple researchers have produced similar recommendations using ANOVA techniques on lathe tests $[72,89,106]$. A study into the sustainable machining of MMC material by Boswell et al. using milling tests supported the conclusion that feed rate was the primary influence on surface roughness, however the results of their testing found that surface finish improved with an increase in feed rate [29] which is 
contrary to conventional wisdom. Another study indicated that at low speeds, particle pull-out has a greater influence on surface roughness than the feed rate [107].

\subsection{Effect of Cutting Depth}

The majority of studies into the machinability of MMCs have yielded corresponding results as to the effects of the depth of cut. Turning studies by Rabindra Behera and G. Sutradhar suggest that an increase in depth of cut yields an increase in total resultant cutting force [108] Several quantitative analyses using methods such as ANOVA upon lathe tests have suggested that the depth of cut has the least significant effect upon the rate of tool wear and the quality of the machined surface finish $[63,72,89,104,109]$. The same result was attained using experimental methods in several other studies $[24,35,110]$. In one of the experimental works, the test results suggested that the best material surface finish was achieved at the lowest depth of cut, and the depth of cut had significant influence upon the cutting force [29]. The study found that the negative impact of a large depth of cut was offset by the benefits of increased material removal rate. Another ANOVA based analysis of the machining parameters by Bansal \& Upadhyay [63] suggested that the depth of cut had more effect upon the tool wear and the surface finish than the feed rate. Another turning study performed by Kishore et al. also suggested that depth of cut had a significant impact upon the tool wear [111]. The implications of these studies suggest that if economical use of tool tips is desirable, the depth of cut should be maximized. If the surface finish is the primary concern, the depth of cut should be minimized in order to reduce the surface roughness.

\subsection{Built-Up Edge}

The benefit of the formation of a built-up edge during the machining of MMCs has been a topic of some controversy among researchers. Many believe it is beneficial to the overall machinability, whereas others believe it should be avoided. The development of a built up edge is reliant upon temperatures at the machining interface that are sufficient to melt the metal matrix material, which may then build up on the machine tool $[41,112]$. It has been suggested that built-up edge occurs ideally at low cutting speeds [113]. Many studies suggest that the controlled formation of a built-up edge will result in an extension of the useful tool life during machining by protecting the tool from abrasive wear [41, 114-116]. It is suggested that the built-up edge protects the tool from the abrasive particle wear caused by the dispersed phase, acting as a sacrificial coating that is constantly replenished as the metal matrix is machined [85] [42]. 
It has been suggested in other research that a built-up edge can be detrimental to tool life during machining [109, 117]. These studies suggest that the built up edge will adhere to the tool tip and as the forces at the tool interface affect the tip the built-up edge will be sheared from the tool tip, removing a portion of the tip in the process [117]. The result of such an occurrence could potentially be a catastrophic failure of the machine tool, requiring an interruption to the machine process, replacement of the tool and potentially destructive effects upon the surface finish of the workpiece [23].

A built-up edge will only provide limited protection from flank wear unless the built-up edge is so large that it causes unacceptable damage to machined surface finish[8]. Irrespective of its size, built-up edge has been shown to yield a measurable decrease in the surface finish of the workpiece $[21,41,118,119]$. The desirability of a sustainable built-up edge will therefore be dependent upon whether the preservation of the machine tool or the quality of the surface roughness is of higher priority. Finishing operations with the presence of a built-up edge are less likely to produce desirable results.

\subsection{Effects of Coolant Selection}

During the machining of traditional materials, tool life and surface finish issues are helped by using coolant to reduce friction and for dissipating the generated heat. A variety of different cooling methods need to be investigated when machining MMCs, as each will yield differing results during machining. As metal matrix composites have developed into a commercially available material, several attempts have been made to determine a suitable method of cooling MMCs during machining, none of which have yielded results comparable to the cooling of traditional materials [119-121]. All of the more mainstream machine coolants that have been applied to traditional materials have been investigated thoroughly for their effects upon the machining of MMCs. Several more unconventional methods have not yet been investigated as a means for cooling MMCs during machining. The investigation of coolants for the machining of MMCs remains an important research topic, as researchers have yet to discover a truly effective method of cooling the heat generating zone of the tool.

\subsection{Dry Machining}

Research into the application of lubricants while machining MMCs has been a focus of many recent studies as researchers attempt to find ways of overcoming the machinability issues 
pertinent to the material. It has been suggested that the use of a cutting fluid could be redundant due to the lack of improvement in the performance of a machine operation under cooling [8]. Dry machining has been applied successfully to conventional materials in the past [122-124]. Conflicting studies suggest that the control of thermal properties at the machining interface will affect both tool life and surface finish $[85,121]$.

Dry machining generally generates significant increases in machining temperature over the use of coolant, meaning the conditions will likely be suitable for the formation of a built-up edge. This means that the practice of dry machining is likely to subject the machining process to the benefits and drawbacks associated with built-up edge. The increased temperatures also increase the risk of wear by diffusion, which occurs when atoms from the reinforcement matrix and the tool tip are exchanged, resulting in a weakened tool tip and the associated negative impact upon the tool's properties [125]. Increases in machining temperature have been shown to lead to an exponential increase in the rate of diffusion wear [126].

\subsection{Flood Machining}

Flood cooling is a well-established method of cooling machining operations, which involves the practice of "flooding" the tool interface with a coolant delivered by a low pressure pump [40]. Flood cooling has been shunned in more recent years due to concerns about environmental and health effects of older cutting fluids [9]. Modern cutting fluids have been developed based upon vegetable oil emulsions and now do not pose a health threat to the machine operator [127] as in the past. Environmental issues are still relevant as the coolant with use will become contaminated and requires suitable disposal measures. This means that the suitability of flood coolant during machining can be assessed based only upon performance and economical criteria.

The use of traditional cutting coolants while machining MMCs was investigated in depth by Hung, Yeo and Oon [119]. They performed a series of cutting operations, removed the built up edge from the used tool and performed measurements to determine the scale of any tool erosion. The results of their investigations concluded that the use of a cutting fluid would neither increase nor decrease the life of a cutting tool.

An investigation on drilling MMCs by Cronjager and Meister suggested that the application of a cutting fluid was responsible for a one sixth reduction of tool life [30]. The theory proposed 
to explain this reduction was that the reduction in temperature assisted the matrix to retain its strength, rather than deforming due to temperature. Another study found that the application of flood coolant had no effect at low cutting speeds, however the machining forces decreased significantly at higher cutting speeds [24]. The same work found that the surface finish deteriorated slightly when flood cooling was applied to the machining process. Cronjager [30] performed drilling and milling tests upon various reinforced aluminum composites, noting that the surface finish decreased when flood cooling was applied during the machining operation.

\subsection{Minimum Quantity Lubrication}

Minimum Quantity Lubrication (MQL) involves the application of an oil, emulsion or water as a fine spray onto the machining interface using air or aerosol as a coolant transport medium [128]. MQL is a relatively recent innovation in machining that has been developed in response to the financial and environmental concerns with the use of flood cooling [129]. MQL has been successfully applied to conventional machining operations and is rapidly becoming one of the most widely utilized methods of lubricating and cooling machine processes.

The viability of applying MQL to MMCs has been investigated in a number of recent research works [120, 130, 131]. Solhjoei et al. [130]performed a series of high speed milling tests with carbide tooling upon samples of alumina reinforced aluminium of varying reinforcement particle concentrations. The results of the study suggested that the use of MQL would yield satisfactory machine surface finish and tool wear when machining $10 \& 15 \%$ alumina reinforced MMC. The same study suggested that MQL was not appropriate for $20 \%$ reinforced MMC due to the extent of the flank wear observed during testing.

Research performed into the use of MQL support its viability as a coolant and lubricant when machining MMCs [131]. Braga et al. [120] performed drilling tests comparing the use of MQL as a lubricant with traditional flood coolant, as well as comparing diamond coated drill bits with K10 carbide drills. The results of the study showed that the use of MQL yielded similar or improved surface finish and tool wear results as the tests performed using flood coolant.

\subsection{Other Cooling Methods}

Compressed air cooling involves the direction of a jet of compressed air into the machining interface. The application of air cooling has been investigated as a coolant for the machining of MMCs [36, 121]. A study by McGinty and Preuss [36] consisting of drilling Aluminium 
plates reinforced with 55\% Alumina fibers compared flood coolant to air cooling. While flood cooling was applied, an abrasive slurry was formed which accelerated the wear to the tool. When air cooling was substituted, the accelerated wear stopped. A study performed by Shetty et al. [121] found compressed air to be a better form of coolant than oil water emulsion, yielding clear improvements in cutting force.

A study by Stjemstoft investigated the effects of pressurized water and $\mathrm{CO}_{2}$ as coolants for the machining of MMCs. The results found a maximum of 5\% increase in tool life when cooling with $\mathrm{CO}_{2}$. In some of the tests conducted using water as a coolant, no significant change to tool life was observed, however it was noted that some damage was caused to the tool by the high pressure jet used to deliver the water [132].

Shetty et al. conducted a study on the feasibility of using steam as a coolant and lubricant. The study also tested oil water emulsions, compressed air and dry cutting as baseline comparison points [121]. The tests performed measured cutting force, thrust force, workpiece coefficient of friction, cutting temperature and surface roughness of the workpiece.

In all tests, steam was found to improve the cutting conditions. Conditions measured for compressed air typically showed cutting forces 5-10\% higher than steam; with results for oil water emulsion and dry cutting varying determined to be $15-35 \%$ worse than steam. The results of the research support the viability of steam as a coolant and lubricant, however the results also identify compressed air as being a medium more promising than traditional cutting fluids or dry machining.

\subsection{Conclusions}

This review has confirmed many of the difficulties experienced when machining MMCs using commercial machining techniques. It has also identified areas of particular concern that contribute to the difficulty of the machining process. The careful selection of the machining parameters, tool type and method of cooling is the key to achieving an economical and accurate cutting process. The selection of a tool material will be the primary concern when seeking to economise the costs of machining. Generally PCD tools proved to be the most appropriate tool having the best lifespans when machined under optimum conditions. Cemented carbide tools may also be commercially viable for use in short run machining or for operations with low cutting speeds and high feed rates. 
The parameters of the machining operation will affect the quality of the machine finish and the rate of wear to the machine tool. The selection of an ideal cutting speed will depend upon the priorities of the operation. Lower cutting speeds will assist in the formation of a built-up edge, which is critical to improving the performance of a cemented carbide tool. The formation of a stable built-up edge is also desirable for the economic performance of other tool types. Higher cutting speeds will result in improved machine surface finishes over the finish produced with a slower cutting speed and a built-up edge. The selection of feed rate is most relevant to the surface finish of the workpiece. Most studies concur that surface finish is improved at lower feed rates, however if surface finish is not of primary concern then the tool life has found to improve under high feed rates. The depth of cut has the least impact upon surface finish and tool wear. Generally speaking, the depth of cut should be maximised in order to remove as much material as possible and improve the economy of the process, however if the quality of the surface finish is of primary importance then the depth of cut can be reduced to improve the surface roughness.

The appropriate application of a coolant can extend the tool lifespan and improve the overall machinability of an MMC workpiece. The available literature suggests that dry machining will often result in damage to the surface finish of the workpiece due to increased machining temperatures and the presence of built up edge. Flood coolant has been found to decrease the tool life due to the difficulty in maintaining a protective BUE. Flood coolant may also form an abrasive slurry with machine chips in some circumstances, which may damage the surface finish of the workpiece. MQL has been shown to produce an effective compromise between extending tool life and protecting the surface finish. The application of any coolant will not yield results as effective as conventional application due to the harsh abrasive nature of the reinforcement particles present in MMCs.

The trend of recent research has shifted to focus more on non-conventional machining techniques than that of conventional machining. These processes include electro-discharge machining (EDM), laser cutting, electro-chemical, electro-chemical discharge and abrasive water jet cutting $[133,134]$. The primary issue observed with the various non-conventional machining methods were issues of surface finish quality or dimensional inaccuracy [135]. Researchers are also examining the economic aspects of non-traditional machining of MMCs which naturally involves the speed of the abrasive electrical discharge and the machining 
energy of EDM [136]. This is also important for electro-chemical machining with researchers investigating better stability and high economic process improving the material removal rate [137]. For abrasive waterjet process to improve economically researchers are interested in how the reinforce particles in the MMCs effect the cutting parameters like the depth of cut [138]. Eliminating the use of traditional coolant and improving the tool life used [139], in conventional machining would provide substantial economic benefits. Research into both conventional and non-conventional methods of machining MMCs continues to develop an overall understanding of the optimal and economical methods of machining MMCs. However, at the current level of development it appears that the use of conventional methods will continue to be used in situations requiring accurate part geometries or good surface finishes.

MMCs continue to develop as a commercial material, especially for ultra-light high strength applications, however there is still much research to be performed in order to optimise the machining of these materials. Analysis of the cutting process of MMCs are increasingly using analytical and computer models to provide optimum solutions [141, 142, and 143]. As yet none of the available tool materials are capable of performing on levels approaching conventional commercial machining operations due to the harsh conditions they are subjected to while machining MMCs. Many of the more common methods of cooling have been shown to have negative effects upon MMC machining operations, meaning there is also a demand for a more ideal method of cooling these operations. Many recent studies have focused upon optimising the machining parameters for MMCs, and have generally concurred upon the general requirements for their ideal machining. Although the research presented in this review demonstrates a significant improvement in the understanding of the machining of MMCs since their inception, a substantial amount of work remains until the MMC machining process is fully understood.

\section{References:}

1. Fridlyander, J.N., Metal Matrix Composites ed. J.N. Fridlyander. 1995, London: London : Chapman \& Hall.

2. Ibrahim, I.A., F.A. Mohamed, and E.J. Lavernia, Particulate reinforced metal matrix composites - a review. 1991. p. 1137-1156.

3. Davim, J.P., Diamond tool performance in machining metal-matrix composites. Journal of Materials Processing Technology, 2002. 128(1-3): p. 100-105.

4. Rai, R.N., et al., A study on the machinability behaviour of Al-TiC composite prepared by in situ technique. Materials Science and Engineering A, 2006. 428(1-2): p. 34-40.

5. Torralba, J.M., C.E. da Costa, and F. Velasco, P/M aluminum matrix composites: an overview. Journal of Materials Processing Technology, 2003. 133(1-2): p. 203-206. 
6. Chawla, N. and K.K. Chawla, Metal Matrix Composites 2013, New York: Springer.

7. Lin, J.T., D. Bhattacharyya, and W.G. Ferguson, Chip formation in the machining of SiC-particle-reinforced aluminium-matrix composites. Compos. Sci. Technol., 1998. 58(2): p. 285-291.

8. Gururaja, S., M. Ramulu, and W. Pedersen, Machining of MMCs: A Review, in Mach. Sci. Technol. 2013. p. 41-73.

9. Shokrani, A., V. Dhokia, and S.T. Newman, Environmentally conscious machining of difficult-to-machine materials with regard to cutting fluids. International Journal of Machine Tools and Manufacture, 2012. 57: p. 83-101.

10. Aronson, R.B., Machining Composites. Manufacturing Engineering, 1999. 122(1): p. 52-59.

11. Quan, Y.M., Z.H. Zhou, and B.Y. Ye, Cutting process and chip appearance of aluminum matrix composites reinforced by SiC particle. Journal of Materials Processing Technology, 1999. 91(1-3): p. 231-235.

12. Kishawy, H.A., S. Kannan, and M. Balazinski, An energy based analytical force model for orthogonal cutting of metal matrix composites. CIRP Annals - Manufacturing Technology, 2004. 53(1): p. 91-94.

13. Dabade, U.A., D. Dapkekar, and S.S. Joshi, Modeling of chip-tool interface friction to predict cutting forces in machining of $\mathrm{Al} / \mathrm{SiCp}$ composites. International Journal of Machine Tools and Manufacture, 2009. 49(9): p. 690-700.

14. Pramanik, A., L.C. Zhang, and J.A. Arsecularatne, Prediction of cutting forces in machining of metal matrix composites. International Journal of Machine Tools and Manufacture, 2006. 46(14): p. 1795-1803.

15. Jeyakumar, S., K. Marimuthu, and T. Ramachandran, Prediction of cutting force, tool wear and surface roughness of Al6061/SiC composite for end milling operations using RSM. Journal of Mechanical Science and Technology, 2013. 27(9): p. 2813-2822.

16. Liu, J., J. Li, and $\mathrm{C} . \mathrm{Xu}$, Interaction of the cutting tools and the ceramic-reinforced metal matrix composites during micro-machining: A review. CIRP Journal of Manufacturing Science and Technology, 2014. 7(2): p. 55-70.

17. Barnes, S. and I.R. Pashby, Machining of Aluminium Based Metal Matrix Composites. Applied Composite Materials, 1995. 2: p. 31-42.

18. Durante, S., G. Rutelli, and F. Rabezzana, Aluminum-based MMC machining with diamond-coated cutting tools. Surface and Coatings Technology, 1997. 94-95(0): p. 632-640.

19. Tomac, N. and K. Tonnessen, Machinability of Particulate Aluminium Matrix Composites. CIRP Annals - Manufacturing Technology, 1992. 41(1): p. 55-58.

20. Haq, A.N., P. Marimuthu, and R. Jeyapaul, Multi response optimization of machining parameters of drilling Al/SiC metal matrix composite using grey relational analysis in the Taguchi method. International Journal of Advanced Manufacturing Technology, 2008. 37(3-4): p. 250-255.

21. Ciftci, I., M. Turker, and U. Seker, CBN cutting tool wear during machining of particulate reinforced MMCs. Wear, 2004. 257(9-10): p. 1041-1046.

22. Ding, X., W.Y.H. Liew, and X.D. Liu, Evaluation of machining performance of MMC with PCBN and PCD tools. Wear, 2005. 259(7-12): p. 1225-1234.

23. Njuguna, M.J., D. Gao, and H. Zhaopeng, Tool Wear, Surface Integrity and Dimensional Accuracy in Turning Al2124SiCp (45\%wt) Metal Matrix Composite using CBN and PCD Tools. Research Journal of Applied Sciences, Engineering and Technology, 2013. 6(22): p. 4138-4144. 
24. Kannan, S., Machining of Metal Matrix Composites: Forces, Tool Wear and Attainable Surface Quality, in Department of Mechanical Engineering. 2006, The University of New Brunswick.

25. El-Gallab, M. and M. Sklad, Machining of Al/SiC particulate metal-matrix composites: Part I: Tool performance. Journal of Materials Processing Technology, 1998. 83(1-3): p. 151-158.

26. Beristain, J., O. Gonzalo, and A. Sanda, Machinability of Al-SiC metal matrix composites using WC, PCD and MCD inserts. Rev. Metal., 2014. 50(1).

27. Hung, N.P., et al., Machinability of aluminum alloys reinforced with silicon carbide particulates. Journal of Materials Processing Technology, 1996. 56(1-4): p. 966-977.

28. Songmene, V. and M. Balazinski, Machinability of Graphitic Metal Matrix Composites as a Function of Reinforcing Particles. CIRP Annals - Manufacturing Technology, 1999. 48(1): p. 77-80.

29. Boswell, B., M.N. Islam, and A. Pramanik, Effect of machining parameters on the surface finish of a metal matrix composite under dry cutting conditions. Proceedings of the Institution of Mechanical Engineers, Part B: Journal of Engineering Manufacture, 2015. DOI: $10.1177 / 0954405415583776$.

30. Cronjäger, L. and D. Meister, Machining of Fibre and Particle-Reinforced Aluminium. CIRP Annals - Manufacturing Technology, 1992. 41(1): p. 63-66.

31. Narahari, P., B.C. Pai, and R.M. Pillai, Some aspects of machining cast Al-SiCp composites with conventional high speed steel and tungsten carbide tools. J. Mater. Eng. Perform., 1999. 8(5): p. 538-542.

32. Teti, R., Machining of Composite Materials. CIRP Annals - Manufacturing Technology, 2002. 51(2): p. 611-634.

33. Chen, P. and T. Hoshi, High-Performance Machining of SiC Whisker-Reinforced Aluminium Composite by Self-Propelled Rotary Tools. CIRP Annals - Manufacturing Technology, 1992. 41(1): p. 59-62.

34. Hung, N.P., et al., Machinability of cast and powder-formed aluminum alloys reinforced with SiC particles. Journal of Materials Processing Technology, 1995. 48(14): p. 291-297.

35. Chambers, A.R., The machinability of light alloy MMCs. Composites Part A: Applied Science and Manufacturing, 1996. 27(2): p. 143-147.

36. Mcginty, M.J. and C.W. Preuss, Machining ceramic fiber metal matrix composites, in Congress on High Productivity in Machining, Materials and Processing, V.K. Sarin, Editor. 1985, ASM International: New Orleans, LA.

37. Basavarajappa, S., G. Chandramohan, and J.P. Davim, Some studies on drilling of hybrid metal matrix composites based on Taguchi techniques. Journal of Materials Processing Technology, 2008. 196(1-3): p. 332-338.

38. Ramulu, M., P.N. Rao, and H. Kao, Drilling of (Al2O3)p/6061 metal matrix composites. Journal of Materials Processing Technology, 2002. 124(1-2): p. 244-254.

39. Taşkesen, A. and K. Kütükde, Experimental investigation and multi-objective analysis on drilling of boron carbide reinforced metal matrix composites using grey relational analysis. Measurement, 2014. 47(0): p. 321-330.

40. Black, J.T., R.A. Kohser, and E.P. DeGarmo, DeGarmo's materials and processes in manufacturing. 10th ed. 2008, Hoboken, NJ: Wiley. xvi. 1010 p.

41. Abdullah, A., Machining of aluminium based metal matrix composite in School of Engineering. 1996, University of Warwick.

42. Pedersen, W. and M. Ramulu, Facing SiCp/Mg metal matrix composites with carbide tools. Journal of Materials Processing Technology, 2006. 172(3): p. 417-423. 
43. Sun, F., et al., High speed milling of SiC particle reinforced aluminum-based MMC with coated carbide inserts, in Key Engineering Materials. 2004. p. 457-462.

44. Ciftci, I., M. Turker, and U. Seker, Evaluation of tool wear when machining SiCpreinforced Al-2014 alloy matrix composites. Mater. Des., 2004. 25(3): p. 251-255.

45. Übeyli, M., et al., Study on performance of uncoated and coated tools in milling of Al4\% Cu/B4C metal matrix composites. Materials Science and Technology, 2007. 23(8): p. 945-950.

46. Quigley, O., J. Monaghan, and P. O'Reilly, Factors affecting the machinability of an Al/SiC metal-matrix composite. Journal of Materials Processing Technology, 1994. 43(1): p. 21-36.

47. Hocheng, H., et al., Fundamental turning characteristics of a tribology-favored graphite/aluminum alloy composite material. Composites Part A: Applied Science and Manufacturing, 1997. 28(9-10): p. 883-890.

48. Yanming, Q. and Z. Zehua, Tool wear and its mechanism for cutting SiC particlereinforced aluminium matrix composites. Journal of Materials Processing Technology, 2000. 100(1-3): p. 194-199.

49. Muthukrishnan, N., Machinability Studies On Fabricated Al Sic B4c Hybrid Metal Matrix Composites By Turning. i-Manager's Journal on Mechanical Engineering, 2012. 2(2): p. 32-40.

50. Kaarmuhilan, K., S. Karthika, and N. Muthukrishnan, Performance Evaluation of PCD 1300 and 1500 Grade Inserts on Turning A356 Alloy with 20\% Reinforcement of SiC Particles. Applied Mechanics and Materials, 2011. 110-116: p. 1855.

51. Joshi, S.S., 17 - Machining metal matrix composites using diamond tools, in Machining Technology for Composite Materials, H. Hocheng, Editor. 2012, Woodhead Publishing. p. 426-459.

52. Tönshoff, H.K. and J. Winkler, The influence of tool coatings in machining of magnesium. Surface and Coatings Technology, 1997. 94-95(0): p. 610-616.

53. Masounave, J., J. Litwin, and D. Hamelin, Prediction of tool life in turning aluminium matrix composites. Materials and Design, 1994. 15(5): p. 287-293.

54. Hung, N.P., N.L. Loh, and Z.M. Xu, Cumulative tool wear in machining metal matrix composites Part II: Machinability. Journal of Materials Processing Technology, 1996. 58(1): p. 114-120.

55. J. R. Davis \& Associates. and ASM International. Handbook Committee., Aluminum and aluminum alloys. ASM specialty handbook. 1993, Materials Park, OH: ASM International. iii, $784 \mathrm{p}$.

56. Paulo Davim, J. and A. Monteiro Baptista, Relationship between cutting force and PCD cutting tool wear in machining silicon carbide reinforced aluminum. Journal of Materials Processing Technology, 2000. 103(3): p. 417-423.

57. Iuliano, L., L. Settineri, and A. Gatto, High-speed turning experiments on metal matrix composites. Composites Part A: Applied Science and Manufacturing, 1998. 29(12): p. 1501-1509.

58. Weinert, K. and W. König, A Consideration of Tool Wear Mechanism when Machining Metal Matrix Composites (MMC). CIRP Annals - Manufacturing Technology, 1993. 42(1): p. 95-98.

59. Cook, M.W., Machining MMC engineering components with polycrystalline diamond and diamond grinding. Mater. Sci. Technol., 1998. 14(9-10): p. 892-895.

60. Chambers, A.R. and S.E. Stephens, Machining of Al $\square 5 \mathrm{Mg}$ reinforced with 5 vol.\% Saffil and 15 vol.\% SiC. Materials Science and Engineering: A, 1991. 135(0): p. 287290. 
61. Chen, P. and Y. Miyake. in Proceedings of 1989 ASM International Conference on Machinability. 1989. Cincinnati.

62. Boopathi, M.M., K.P. Arulshri, and N. Iyandurai, Evaluation of Mechanical Properties of Aluminium Alloy 2024 Reinforced with Silicon Carbide and Fly Ash Hybrid Metal Matrix Composites. American Journal of Applied Sciences, 2013. 10(3): p. 219-229.

63. Bansal, P. and L. Upadhyay, Experimental Investigations to Study Tool Wear During Turning of Alumina Reinforced Aluminium Composite. Procedia Engineering, 2013. 51(0): p. 818-827.

64. Brun, M.K., M. Lee, and F. Gorsler, Wear characteristics of various hard materials for machining sic-reinforced aluminum alloy. Wear, 1985. 104(1): p. 21-29.

65. Andrewes, C.J.E., H.-Y. Feng, and W.M. Lau, Machining of an aluminum/SiC composite using diamond inserts. Journal of Materials Processing Technology, 2000. 102(1-3): p. 25-29.

66. Kremer, A. and M. El Mansori, Influence of nanostructured CVD diamond coatings on dust emission and machinability of SiC particle-reinforced metal matrix composite. Surface and Coatings Technology, 2009. 204(6-7): p. 1051-1055.

67. Wang, Y.J., et al., Tool Wear in High Speed Milling of SiCp/Al2024 Metal Matrix Composites. Applied Mechanics and Materials, 2010. 33: p. 200.

68. Kremer, A., et al., Machinability of AI/SiC Particulate Metal-Matrix Composites Under Dry Conditions With CVD Diamond-Coated Carbide Tools. Machining Science and Technology, 2008. 12(2): p. 214-233.

69. Chou, Y.K. and J. Liu, CVD diamond tool performance in metal matrix composite machining. Surface and Coatings Technology, 2005. 200(5-6): p. 1872-1878.

70. Smith, G.T., Cutting tool technology : industrial handbook. 2008, London: Springer. xii, 599 p.

71. Looney, L.A., et al., The turning of an Al/SiC metal-matrix composite. Journal of Materials Processing Technology, 1992. 33(4): p. 453-468.

72. Saravanan, T. and R. Udayakumar, Optimization of Machining Hybrid Metal Matrix Composites Using Desirability Analysis. Middle-East Journal of Scientific Research 2013. 15(12): p. 1691-1697.

73. El-Gallab, M. and M. Sklad, Machining of Al/SiC particulate metal matrix composites: Part II: Workpiece surface integrity. Journal of Materials Processing Technology, 1998. 83(1-3): p. 277-285.

74. Suresh Kumar Reddy, N., S. Kwang-Sup, and M. Yang, Experimental study of surface integrity during end milling of Al/SiC particulate metal-matrix composites. Journal of Materials Processing Technology, 2008. 201(1-3): p. 574-579.

75. Cheung, C.F., et al., Effect of reinforcement in ultra-precision machining of Al6061/SiC metal matrix composites. Scripta Materialia, 2002. 47(2): p. 77-82.

76. Said, M.S., et al., Tool wear in machining AlSi/AlN metal matrix composite $10 \mathrm{Wt} \%$ reinforcement using uncoated cutting tool, in Applied Mechanics and Materials. 2014. p. 973-977.

77. Pandi, G. and S. Muthusamy, A Review on Machining and Tribological Behaviors of Aluminium Hybrid Composites. Procedia Engineering, 2012. 38: p. 1399-1408.

78. Manna, A. and B. Bhattacharayya, Influence of machining parameters on the machinability of particulate reinforced $\mathrm{Al} / \mathrm{SiC}-\mathrm{MMC}$. The International Journal of Advanced Manufacturing Technology, 2005. 25(9-10): p. 850-856.

79. Palanikumar, K., N. Muthukrishnan, and K.S. Hariprasad, Surface rougness parameters optimising in machining A356/SiC/20p metal matrix composites by PCD tool using response surface methodology and desirability function. Mach. Sci. Technol., 2008. 12(4): p. 529-545. 
80. Srinivasan, A., et al., Machining Performance Study on Metal Matrix Composites-A Response Surface Methodology Approach. American Journal of Applied Sciences, 2012. 9(4): p. 478.

81. Manna, A. and B. Bhattacharayya, A study on machinability of Al/SiC-MMC. Journal of Materials Processing Technology, 2003. 140(1-3): p. 711-716.

82. Ozcatalbas, Y., Investigation of the machinability behaviour of Al4C3 reinforced Albased composite produced by mechanical alloying technique. Composites Science and Technology, 2003. 63(1): p. 53-61.

83. Karakaş, M.S., et al., Effect of cutting speed on tool performance in milling of B4Cp reinforced aluminum metal matrix composites. Journal of Materials Processing Technology, 2006. 178(1-3): p. 241-246.

84. Sahin, Y., Preparation and some properties of SiC particle reinforced aluminium alloy composites. Materials \& Design, 2003. 24(8): p. 671-679.

85. Davim, J.P., Machining of Metal Matrix Composites / edited by J. Paulo Davim, ed. SpringerLink. 2012, London: London : Springer London.

86. Kannan, S., M. Balazinski, and H.A. Kishawy, Flank Wear Progression During Machining Metal Matrix Composites. Journal of Manufacturing Science and Engineering, 2005. 128(3): p. 787-791.

87. Premnath, A.A., T. Alwarsamy, and T. Rajmohan, Experimental Investigation and Optimization of Process Parameters in Milling of Hybrid Metal Matrix Composites. Materials and Manufacturing Processes, 2012. 27(10): p. 1035-1044.

88. Bhushan, R.K., Optimization of cutting parameters for minimizing power consumption and maximizing tool life during machining of Al alloy SiC particle composites. Journal of Cleaner Production, 2012. 39: p. 242-254.

89. Vibu Nanthan, M., C. Vidhusan, and S. Vignesh, Machinability Studies of Turning Al/SiC/B4C Hybrid Metal Matrix Composites using ANOVA Analysis, in International Conference on Thermal, Material and Mechanical Engineering. 2012: Singapore.

90. Davim, J.P., Design of optimisation of cutting parameters for turning metal matrix composites based on the orthogonal arrays. Journal of Materials Processing Technology, 2003. 132(1-3): p. 340-344.

91. Ozcatalbas, Y., Chip and built-up edge formation in the machining of in situ Al4C3-Al composite. Materials \& Design, 2003. 24(3): p. 215-221.

92. Kumar, A., M.M. Mahapatra, and P.K. Jha, Effect of machining parameters on cutting force and surface roughness of in situ Al-4.5\%Cu/TiC metal matrix composites. Measurement, 2014. 48(0): p. 325-332.

93. Basavarajappa, S., et al., Drilling of hybrid metal matrix composites-Workpiece surface integrity. International Journal of Machine Tools and Manufacture, 2007. 47(1): p. 92-96.

94. ÜBeylï, M., et al., Effect of Feed Rate on Tool Wear in Milling of Al-4\%Cu/B4 Cp Composite. Materials \& Manufacturing Processes, 2008. 23(8): p. 865-870.

95. Ekici, E., G. Samtaş, and M. Gülesin, Experimental and Statistical Investigation of the Machinability of Al-10\% SiC MMC Produced by Hot Pressing Method. Arabian Journal for Science and Engineering, 2014. 39(4): p. 3289-3298.

96. Anandakrishnan, V. and A. Mahamani, Investigations of flank wear, cutting force, and surface roughness in the machining of Al-6061-TiB2 in situ metal matrix composites produced by flux-assisted synthesis. The International Journal of Advanced Manufacturing Technology, 2011. 55(1-4): p. 65-73.

97. Lin, J.T., D. Bhattacharyya, and C. Lane, Machinability of a silicon carbide reinforced aluminium metal matrix composite. Wear, 1995. 181-183, Part 2(0): p. 883-888. 
98. Finn, M. and A. Srivatsava, Machining of Advanced and Engineered Materials. Proceedings of the CSME Symposium, 1996: p. 616-623.

99. Ozben, T., E. Kilickap, and O. Çakır, Investigation of mechanical and machinability properties of SiC particle reinforced Al-MMC. Journal of Materials Processing Technology, 2008. 198(1-3): p. 220-225.

100. Pendse, D.M. and S.S. Joshi, Modeling and optimization of machining process in discontinuously reinforced aluminium matrix composites. Mach. Sci. Technol., 2004. 8(1): p. 85-102.

101. Gaitonde, V.N., S.R. Karnik, and J.P. Davim, Some Studies in Metal Matrix Composites Machining using Response Surface Methodology. Journal of Reinforced Plastics and Composites, 2009. 28(20): p. 2445-2457.

102. Dabade, U.A., et al., Surface finish and integrity of machined surfaces on Al/SiCp composites. Journal of Materials Processing Technology, 2007. 192-193(0): p. 166174.

103. Radhika, N., R. Subramaniam, and S.B. senapathi, Machining parameter optimisation of an aluminium hybrid metal matrix composite by statistical modelling. Industrial Lubrication and Tribology, 2013. 65(6): p. 425-435.

104. Chandrasekaran, M. and D. Devarasiddappa, Development of Predictive Model for Surface Roughness in End Milling of Al-SiCp Metal Matrix Composites using Fuzzy Logic. World Academy of Science, Engineering and Technology, 2012. 67: p. 930 935.

105. Kilickap, E., et al., Study of tool wear and surface roughness in machining of homogenised SiC-p reinforced aluminium metal matrix composite. J. Mater. Process. Technol., 2005. 164: p. 862-867.

106. Babu, T.S.M. and N. Muthukrishnan, An Experimental Investigation and Optimization of Turning Fabricated Al/SiC/B4C Hybrid Metal Matrix Composites using Desirability Analysis. i-Manager's Journal on Mechanical Engineering, 2012. 2(4): p. 10-17.

107. Pramanik, A., L. Zhang, and J. Arsecularatne, Machining of metal matrix composites: effect of ceramic particles on residual stress, surface roughness and chip formation. 2008.

108. Rabindra, B. and G. Sutradhar, Machinability of LM6/SiCp metal matrix composites with tungsten carbide cutting tool inserts. Journal of Engineering and Applied Sciences, 2012. 7(2): p. 216.

109. Muthukrishnan, N., M. Murugan, and K. Prahlada Rao, Machinability issues in turning of Al-SiC (10p) metal matrix composites. The International Journal of Advanced Manufacturing Technology, 2008. 39(3-4): p. 211-218.

110. Yuan, Z.J., L. Geng, and S. Dong, Ultraprecision Machining of SiCw/Al Composites. CIRP Annals - Manufacturing Technology, 1993. 42(1): p. 107-109.

111. Kishore, D.S.C., K.P. Rao, and A. Mahamani, Investigation of Cutting Force, Surface Roughness and Flank Wear in Turning of In-situ Al6061-TiC Metal Matrix Composite. Procedia Materials Science, 2014. 6(0): p. 1040-1050.

112. Ramaswami, R., The effect of the built-up-edge(BUE) on the wear of cutting tools. Wear, 1971. 18(1): p. 1-10.

113. Sahin, Y., The effects of various multilayer ceramic coatings on the wear of carbide cutting tools when machining metal matrix composites. Surface and Coatings Technology, 2005. 199(1): p. 112-117.

114. Karthikeyan, R., et al., Optimizing the milling characteristics of Al-SiC particulate composites. Metals and Materials, 2000. 6(6): p. 539-547.

115. Cronjager, L. and D. Biermann. in European Conference on Advanced Materials and Processes 1991. Cambridge. 
116. Seeman, M., et al., Study on tool wear and surface roughness in machining of particulate aluminum metal matrix composite-response surface methodology approach. Int. J. Adv. Manuf. Technol., 2010. 48(5-8): p. 613-624.

117. Hocheng, H., Machining technology for composite materials : principles and practice. Woodhead Publishing in materials. 2012, Cambridge, UK ; Philadelphia, PA: Woodhead Pub. xv, 472 p.

118. Dabade, U. and S. Joshi, Machining of Al/SiCp Metal Matrix Composites at Low Temperature Heating Prior to Machining. Applied Mechanics and Materials, 2012. 197: p. 428.

119. Hung, N.P., S.H. Yeo, and B.E. Oon, Effect of cutting fluid on the machinability of metal matrix composites. Journal of Materials Processing Technology, 1997. 67(1-3): p. 157-161.

120. Braga, D.U., et al., Using a minimum quantity of lubricant (MQL) and a diamond coated tool in the drilling of aluminum-silicon alloys. Journal of Materials Processing Technology, 2002. 122(1): p. 127-138.

121. Shetty, R., et al., Steam as coolant and lubricant in turning of metal matrix composites. An international applied physics \& engineering journal, 2008. 9(9): p. 1245-1250.

122. Graham, D., D. Huddle, and D. McNamara, Machining dry is worth a try. Modern Machine Shop, 2003. 76(5): p. 79.

123. Heine, H.J., Dry machining-a promising option. American Machinist, 1997. 141(8): p. 92.

124. Canter, N., The possibilities and limitations of dry machining. Tribology and Lubrication Technology, 2009. 65(3): p. 40-44.

125. Molinari, A. and M. Nouari, Modeling of tool wear by diffusion in metal cutting. Wear, 2002. 252(1-2): p. 135-149.

126. El-Hofy, H., Fundamentals of machining processes : conventional and nonconventional processes. Second edition. ed. 2014, Boca Raton: CRC Press, Taylor \& Francis Group 2014. xliii, 517 pages.

127. Cetin, M.H., et al., Evaluation of vegetable based cutting fluids with extreme pressure and cutting parameters in turning of AISI 304L by Taguchi method. Journal of Cleaner Production, 2011. 19(17-18): p. 2049-2056.

128. Weinert, K., et al., Dry Machining and Minimum Quantity Lubrication. CIRP Annals Manufacturing Technology, 2004. 53(2): p. 511-537.

129. Astakhov, V.P., Metal cutting theory foundations of near-dry (MQL) machining. 2010, Gen\&\#232;ve, SUISSE: Inderscience Publishers. 16.

130. Solhjoei, N., et al., High Speed Milling of Al203 Particles Reinforced Aluminium MMC. Research Journal of Applied Sciences, Engineering and Technology, 2012. 4(17): p. 3015-3020.

131. Davim, J.P., P.S. Sreejith, and J. Silva, Some studies about machining of MMC'S by MQL(Minimum Quantity of Lubricant) Conditions. Advanced Composites Letters, 2009. 18(1): p. 21-23.

132. Stjernstoft, T., Machining of Some Difficult-to-Cut Materials with Rotary Cutting Tools 2004, Industriell produktion: Stockholm.

133. Müller, F. and J. Monaghan, Non-conventional machining of particle reinforced metal matrix composites. Journal of Materials Processing Technology, 2001. 118(1-3): p. 278-285.

134. Ramulu, M. and M. Taya, EDM machinability of SiCw/Alcomposites. Journal of Materials Science, 1989. 24(3): p. 1103-1108. 
135. Pramanik, A., Developments in the non-traditional machining of particle reinforced metal matrix composites. International Journal of Machine Tools and Manufacture, 2014. 86(0): p. 44-61.

136. Jiang-Wen, L., et al., High speed abrasive electrical discharge machining of particulate reinforced metal matrix composites. International Journal of Precision Engineering and Manufacturing, 2015. 16(7): p. 1399-1404.

137. Satishkumar, P., et al., Investigation on eletronchemical micro machining of AL 6061$6 \%$ wt Gr based on Taguchi design of experiments. International Journal of Chem Tech Research, 2015. 7(1): p. 203-211.

138. Mohankumar, V. and Kanthababu M., Review on machining aspects in metal matrix and ceramic matrix composites using abrasive waterjet. Applied Mechanics and Materials, 2015. 766(9): p. 643-648.

139. Aramesh, M., et al., Estimating the remaining usful tool life of worn tools under different cutting parameters:A survival life analysis during turning of titanium metal matrix composites (Ti-MMCs). CIRP Journal of Manufacturing Science and Technology, 2015. CIRPJ-341: pp. 9.

140. Ghandeharium, A., et al., Machining metal matrix composites: novel analytical force model. International Journal of Advance Manufacture Technology, 2015. DOI 10.1007/s00170-015-7554-8: pp. 9.

141. Ghandeharium, A., et al., Analysis of tool-particle interactions during cutting process of metal matrix composites. International Journal of Advance Manufacture Technology, 2015. DOI 10.1007/s00170-015-7346-1: pp. 10.

142. Ghandeharium, A., et al., On tool-workpiece interactions during machining metal matrix composites: investigation of the effect of cutting speed. International Journal of Advance Manufacture Technology, 2015. DOI 10.1007/s00170-015-7869-5: pp. 13. 